\title{
A Theoretical Study of Substituted Cyclobutanones and Their Enols
}

\author{
Mohammad I. Sway, Iyad D. Al-Shawabkeh, and Salim M. Khalil \\ Chemistry Department, College of Science, University of Mutah, Karak, Jordan \\ Reprint requests to Prof. S. M. K.; E-mail: quokhalil@ mutah.edu.jo
}

Z. Naturforsch. 59a, 838 - 844 (2004); received February 23, 2004

MINDO-Forces calculations have been performed with complete optimization of the geometry on cyclobutanone and its enol counterpart, perfluorination of cyclobutanones and enol counterparts, and $\mathrm{X}$-cycolobutanones and their $\mathrm{X}$-enols, where $\mathrm{X}$ is $\mathrm{NO}_{2}, \mathrm{CF}_{3}, \mathrm{CN}, \mathrm{OH}, \mathrm{NH}_{2}$ and $\mathrm{F}$. It was found that ketone is more stable than its enol counterpart. Perfluorination destabilizes ketone on the expense of enol. These results agree with experimental and theoretical calculations. Electron releasing substituents $\left(\mathrm{NH}_{2}, \mathrm{OH}, \mathrm{F}\right)$ stabilize cyclobutanone, while electron withdrawing substituents $\left(\mathrm{CF}_{3}, \mathrm{NO}_{2}\right)$ destabilize it. CN substituents have almost no effect on the stabilization of this keto-enol system.

Geometrical parameters, heats of formation, electron densities and Gibbs free energy are reported.

Key words: Perfluorocyclobutanones; Substituted Cyclobutanones; Keto-enol Equilibria.

\section{Introduction}

Processes involving proton transfer between interconversion tautomers are of fundamental importance in synthetic and mechanistic chemistry. The tautomeric interconversions are keto-enol [1], imine-enamine [2], oxime-nitroso [3], hydrazo-azo [4], and phenol-keto [5]. Among these processes, the most studied form of tautomerism is that between a carbonyl compound (keto form) and its enol form. Most keto forms are thermodynamically more stable than their enol counterparts by more than $10 \mathrm{kcal} / \mathrm{mol}$ [6]. This results in an equilibrium constant $K_{\text {eq }}=[\mathrm{enol}] /[$ keto $]<10^{-8}$. Because of the very low concentration of the short-lived enol forms, $K_{\text {eq }}$ could not be accurately evaluated until a new method of detecting unstable enol tautomers was developed [7]. However, there are known stable enols, for example acetylacetone [8], in which the hydrogen bonding enhances enol stability relative to the keto form.

The molecular structure of cyclobutanone has been investigated by microwave [9] and infrared [10] studies. It was found that the ring is planar. Electron diffraction studies have shown that cyclobutanone ring is not planar (puckered: the beta carbon is outside the plane of the two $\alpha$-carbons and the carbonyl carbon) [11]. Ab initio calculations [12] show that the deformation (puckering) is very small, which almost agrees with microwave and infrared studies.
Bekker et al., described the synthesis of highly fluorinated simple keto-enol systems with dramatically contrasting properties [13]. They found amazingly stable enols, resisting the influence of powerful acids such as sulfuric acid. Lindner et al. found experimentally that $2 \mathrm{H}$-perfluorocyclobutanone (all the hydrogen atoms are replaced by fluorine atoms except one hydrogen atom at the $\alpha$-position of the carbonyl group) is less stable than perfluorocyclobut-1-enol (enol counterpart) [14], i.e. perfluorination destabilized ketone. In contrast, the HF method [14] could not predict this keto-enol equilibrium in the right direction. B3LYP calculations [15] for ketones (2H-Perfluorocyclobutanone and 2,2H-Perfluorocyclobutanone) and their enol counterparts were carried out at various levels of the theory. At the B3LYP/6-31G** and B3LYP/6$31+\mathrm{G}^{*}$ levels, $2 \mathrm{H}$-Perfluorocyclobutanone is more stable than its enol counterpart. But the order of stability reverses at a larger basis set, that is, B3LYP/6$311++\mathrm{G}^{* *} / / \mathrm{B} 3 \mathrm{LYP} / 6-31+\mathrm{G}^{*}$ at which enol becomes $1.0 \mathrm{kcal} / \mathrm{mol}$ more stable than ketone. This fact agrees with the thermodynamic equilibrium constant between ketone and enol [14]. In the case of 2,2H-Perfluorocyclobutanone it was found that the ketone is more stable than its enol counterpart [15].

The aim of the present work is to utilize quantum chemical calculations to provide predictions of the heat of formation, geometry, electron density distribution and stability of cyclobutanone and cyclobut1-enol, and to study the effect of perfluorination and 
substituents such as $\mathrm{CF}_{3}, \mathrm{NO}_{2}, \mathrm{CN}, \mathrm{NH}_{2}, \mathrm{OH}$ and $\mathrm{F}$ on this keto-enol system.

The heat of formation of the substituted keto-enol system is obtained by the semiempirical MINDOForces MO method [16]. The molecular energy of the substituted keto-enol system obtained by the MINDO/3 method [17] was completely minimized by the Murtagh-Sargent minimization technique [18]. The derivative of the energy was calculated with Pulay's force method [19]. The program allows the variation of the beta parameter with the geometrical change in a consistent way. A full description of the program and its application is given in [16a].

\section{Results and Discussion}

\subsection{Parent Cyclobutanone and its Enol Counterpart with Perfluorination}

Cyclobutanone $\mathbf{1}$ has two structures, planar and puckered. The ring puckering is defined as the dihedral angle theta between the two planes $\mathrm{C} 4 \mathrm{C} 1 \mathrm{C} 2$ and C2C3C4.<smiles>O=[Ge]1[CH][CH][CH]1</smiles>

In the present work we have calculated the heats of formation of puckered cyclobutanone at different dihedral angles (theta) and found -36.637 , $-37.935,-38.233,-38.753,-39.032,-39.346$, and $-39.502 \mathrm{kcal} / \mathrm{mol}$ for theta $=30,25,20,15,5$, and 0 degrees respectively. It can be seen from these calculations, that there is a decrease in the heat of formation as the dihedral angle theta decreases. This suggests that the planar structure is more stable than the puckered one, and this agrees with the experimental values $[9,10]$ and theoretical calculation [12].

The calculated heat of formation of cyclobut-1-enol 2, using the MINDO-Forces method [16], was found to be $-28.864 \mathrm{kcal} / \mathrm{mol}$, which agrees with quantum studies [20,21].

The $\mathrm{C} 1 \mathrm{O} 1$ bond length of cyclobut-1-enol 2 is $1.314 \AA$ (Table 1) and remarkably shorter than that of saturated alcohols. Values of $1.425 \AA$ and 1.431 were reported for methanol [22] and ethanol [23], respectively. This observation might be explained by the par-

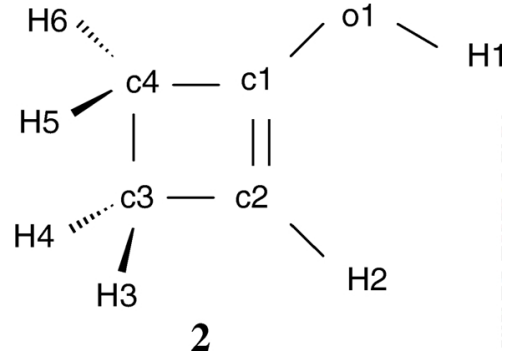

tial double bond character in the case of cyclobut-1enol 2, which originates from the interaction between for $\mathrm{C} 1=\mathrm{C} 2$ double bond and the lone pairs on the oxygen atom. The $\mathrm{C} 1=\mathrm{C} 2$ bond length is $1.362 \AA$ (Table 1 ) which is slightly longer than the corresponding bond

Table 1. Calculated geometrical parameters (bond lengths in Angstroms and bond angles in degrees) of substituted cyclobutanones and their enols.

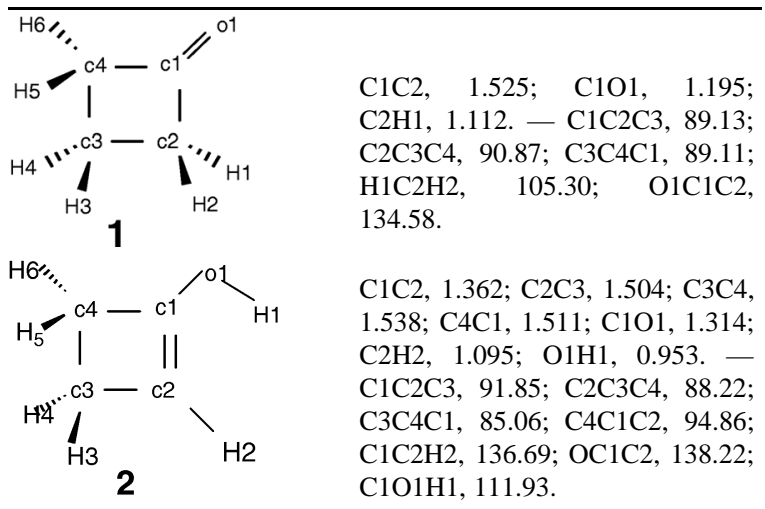

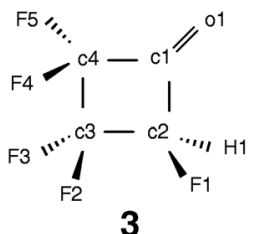

C1C2, 1.528; C2C3, 1.511; C1O1, 1.188; C2H1, 1.106; C2F1, 1.396; $\mathrm{C} 2 \mathrm{~F} 1,1.396 .-\mathrm{C} 1 \mathrm{C} 2 \mathrm{C} 3,89.58$; C2C3C4, 90.87; C3C4C1, 89.66; $\mathrm{C} 1 \mathrm{C} 2 \mathrm{H} 1,118.4$; C1C2F1, 109.72; H1C2F1, 106.17; O1C1C2, 135.37.

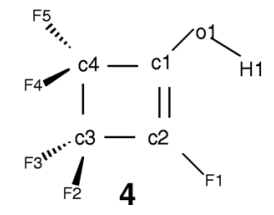

C1C2, 1.362; C2C3, 1.472; C3C4, 1.520; C4C1, 1.497; C1O1, 1.304; $\mathrm{C} 2 \mathrm{~F} 1,1.373$; O1H1, 0.956. C1C2C3, 95.03; C2C3C4, 86.10; C3C4C1, 87.74; C4C1C2, 91.13; C1O1H1, 110.47.

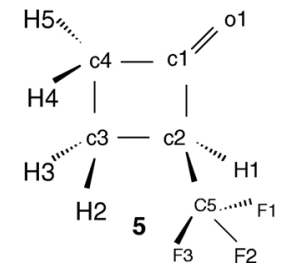

C1C2, 1.556; C2C3, 1.551; C3C4, 1.522; C1O1, 1.187; C2H1, 1.120; $\mathrm{C} 2 \mathrm{C} 5,1.467 ; \mathrm{C} 5 \mathrm{~F} 1,1.327$. C1C2C3, 87.49; C2C3C4, 91.45; C3C4C1, 89.77; C4C1C2, 91.25; O1C1C2, 132.78 . 
Table 1 (continued).

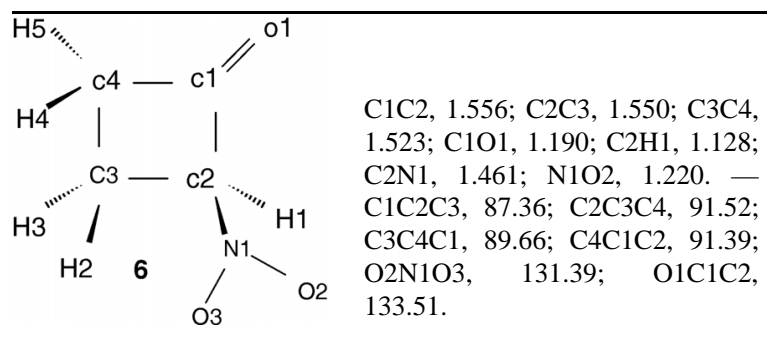

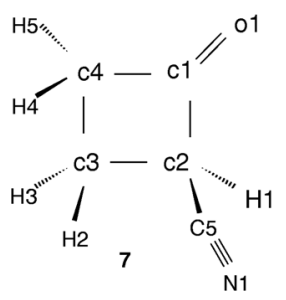

C1C2, 1.546; C2C3, 1.546; C3C4, 1.524; C1O1, 1.194; C2H1, 1.122; C2C5, 1.464; C5N1, 1.163. C1C2C3, 87.81; C2C3C4, 91.48; $\mathrm{C} 3 \mathrm{C} 4 \mathrm{C} 1,89.30 ; \mathrm{C} 4 \mathrm{C} 1 \mathrm{C} 2,91.38$; O1C1C2, 133.76 .

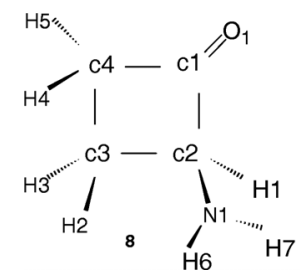

C1C2, 1.544; C2C3, 1.546; C3C4, 1.526; C1O1, 1.195; C2H1, 1.137; C2N1, 1.413; N1H6, 1.029. C1C2C3, 88.08; C2C3C4, 91.20; C3C4C1, 89.50; O1C1C2, 134.58.

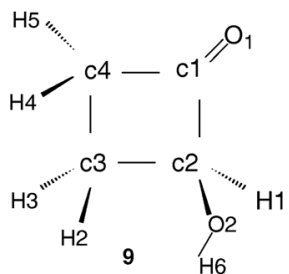

C1C2, 1.550; C2C3, 1.543; C3C4, 1.524; C1O1, 1.194; C2H1, 1.136; C2O2, 1.351; O2H6, 0.953. C1C2C3, 88.62; C2C3C4, 90.72; C3C4C1, 90.24; C4C1C2, 90.41; O1C1C2, 135.28.

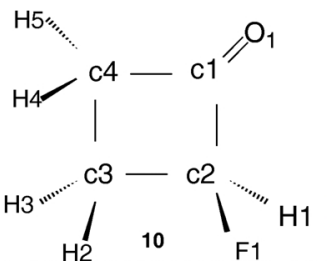

C1C2, 1.520; C2C3, 1.516; C3C4, 1.528; C1O1, 1.193; C2H1, 1.111; C2F1, 1.399. - C1C2C3, 90.69; C2C3C4, 89.75; C3C4C1, 89.94; C4C1C2, 89.58; O1C1C2,135.30.

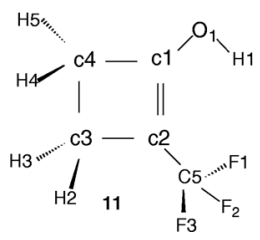

$\mathrm{C} 1 \mathrm{C} 2,1.396 ; \mathrm{C} 2 \mathrm{C} 3,1.528 ; \mathrm{C} 3 \mathrm{C} 4$, 1.525; $\mathrm{C} 4 \mathrm{C} 1,1.511 ; \mathrm{C} 1 \mathrm{O} 1$, 1.295; C2C5, 1.425; C5F1, 1.322; $\mathrm{O} 1 \mathrm{H} 1,0.956 .-\mathrm{C} 1 \mathrm{C} 2 \mathrm{C} 3,90.30$; C2C3C4, 88.93; C3C4C1, 90.28; C4C1C2, 95.03; O1C1C2, 133.48.

length $1.336 \AA$ of vinyl alcohol [24] and $1.326 \AA$ of ethylene [25]. This might be due to the ring strain of cyclobut-1-enol 2.

It can be seen from the calculated heats of formation (Table 2) of cyclobutanone $1(-39.502 \mathrm{kcal} / \mathrm{mol})$
Table 1 (continued).

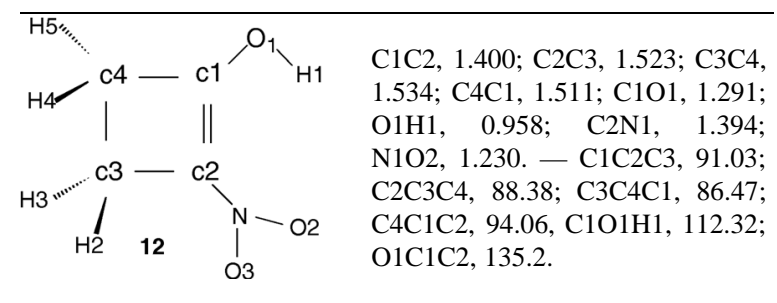

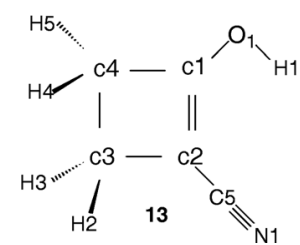

C1C2, 1.384; C2C3, 1.520; C3C4, 1.534; $\mathrm{C} 4 \mathrm{C} 1, \quad 1.511 ; \mathrm{C} 1 \mathrm{O} 1$, 1.309; C2C5, 1.438; C5N1, 1.162; O1H1, 0.956. - C1C2C3, 90.68; C2C3C4, 88.73; C3C4C1, 85.62; $\mathrm{C} 4 \mathrm{C} 1 \mathrm{C} 2,95.05 ; \mathrm{C} 1 \mathrm{O} 1 \mathrm{H} 1,110.08$; O1C1C2, 134.3.

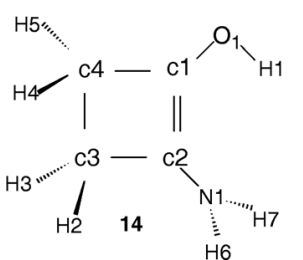

C1C2, 1.347; C2C3, 1.517; C3C4, 1.534; C4C1, 1.509; C1O1, 1.322; C2N1, 1.380; N1H6, 1.027; $\mathrm{O} 1 \mathrm{H} 1,0.954$. - C1C2C3, 91.63; C2C3C4, 88.00; C3C4C1, 85.95; C4C1C2, 94.48; C1O1H1, 110.30; O1C1C2, 137.03.

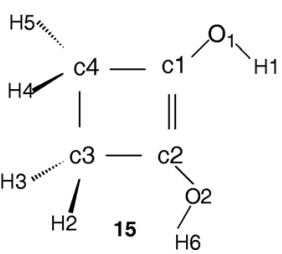

C1C2, 1.370; C2C3, 1.519; C3C4, 1.534; C4C1, 1.512; C1O1, 1.323; $\mathrm{C} 2 \mathrm{O} 2, \quad 1.328 ; \quad \mathrm{O} 2 \mathrm{H} 6, \quad 0.951$; $\mathrm{O} 1 \mathrm{H} 1,0.954$. - C1C2C3, 93.49; C2C3C4, 86.58; C3C4C1, 87.20; C4C1C2, 92.69; C1O1H1, 109.62; O1C1C2, 138.40 .

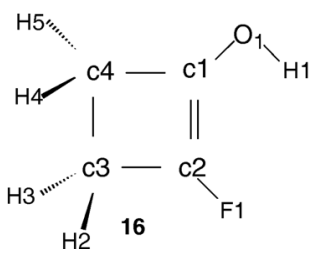

C1C2, 1.351; C2C3, 1.494; C3C4, 1.537; C4C1,1.510; C1O1, 1.319; $\mathrm{C} 2 \mathrm{~F} 1,1.375 ; \mathrm{O} 1 \mathrm{H} 1,0.954$. C1C2C3, 95.57; C2C3C4, 58.25; C3C4C1, 87.64; C4C1C2, 91.54; O1C1C2, 139.37; C101H1, 109.80.

Table 2. Calculated heats of formation $\left(\Delta H_{\mathrm{f}}\right.$ in $\left.\mathrm{kcal} / \mathrm{mol}\right)$ of substituted cyclobutanones and their enols (see Table 1 for numbering).

\begin{tabular}{lccccc}
\hline Compd \# & $\Delta H_{\mathrm{f}}$ & Compd \# & $\Delta H_{\mathrm{f}}$ & Compd \# & $\Delta H_{\mathrm{f}}$ \\
\hline $\mathbf{1}$ & -39.502 & $\mathbf{8}$ & -40.303 & $\mathbf{1 5}$ & -83.426 \\
$\mathbf{2}$ & -28.864 & $\mathbf{9}$ & -85.729 & $\mathbf{1 6}$ & -80.796 \\
$\mathbf{3}$ & -300.575 & $\mathbf{1 0}$ & -91.432 & & \\
$\mathbf{4}$ & -298.256 & $\mathbf{1 1}$ & -235.042 & & \\
$\mathbf{5}$ & -228.185 & $\mathbf{1 2}$ & -58.459 & & \\
$\mathbf{6}$ & -46.500 & $\mathbf{1 3}$ & -14.476 & & \\
$\mathbf{7}$ & -15.799 & $\mathbf{1 4}$ & -38.071 & & \\
\hline
\end{tabular}

and cyclobut-1-enol $2(-28.864 \mathrm{kcal} / \mathrm{mol})$, that cyclobutanone $\mathbf{1}$ is more stable than its enol counterpart 2 by $10.638 \mathrm{kcal} / \mathrm{mole}$ in terms of heat of formation, which agrees well with the experimental value [6] and 


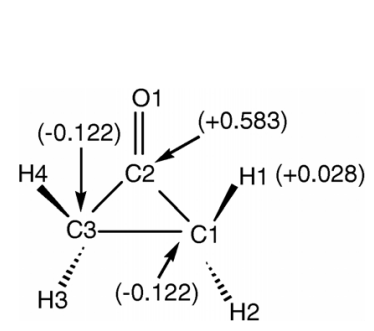

[27]

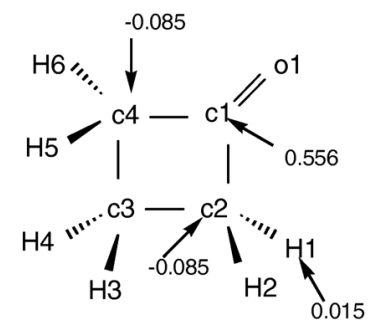

1

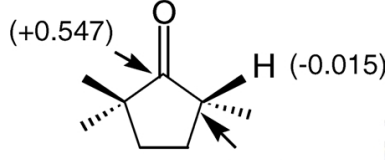

$(-0.076)$

[28] is supported by the calculation of the Gibbs free energy $(\Delta G)$, which is found to be $7.792 \mathrm{kcal} / \mathrm{mol}$.
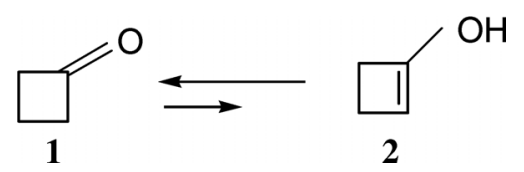

This indicates that the reaction is not spontaneous and the reaction shifts to the cyclobutanone 1 side (reactant). This agrees with the published theoretical calculations [26].

Recent thermodynamic calculations of the Gibbs free energies $(\Delta G)$ of cyclopropanone-cyclopropenol [27] and cyclopentanone-cyclopentenol [28] show that the values of $\Delta G$ are $17.509 \mathrm{kcal} / \mathrm{mol}$ and $5.311 \mathrm{kcal} / \mathrm{mol}$, respectively. From these values it can be seen that $\Delta G$ decreases from the three member ring ( $\Delta G=17.509 \mathrm{kcal} / \mathrm{mol}$ ), to the four and five member $\operatorname{ring}(\Delta G=7.792 \mathrm{kcal} / \mathrm{mol}$ and $\Delta G=5.311 \mathrm{kcal} / \mathrm{mol})$, suggesting an increase of the enol tautomer when going from three member ring to five member ring. This may be due to a decrease in the ring strain of the enol tautomer when going from the three to the five member ring. Also it was noticed that the electrostatic attraction between the carbonyl carbon and the $\alpha$-carbons decreases when going from three member ring [27], to four (present results) and five member ring [28], suggesting an increase in the destabilization of the ketone tautomer in going from the three member to the five member ring.

On perfluorination of the keto-enol system, the calculated heats of formation of $2 \mathrm{H}$-perfluorocyclobutanone $\mathbf{3}$ and the enol counterpart perfluorocyclobut-1-enol 4 (Table 2) are -300.575 and $-298.256 \mathrm{kcal} / \mathrm{mole}$, respectively. Thus the difference in the heat of formation is reduced to $2.319 \mathrm{kcal} / \mathrm{mol}$ as compared to the parent (without perfluorination, $10.638 \mathrm{kcal} / \mathrm{mol}$ ). Therefore the perfluorination process causes a destabilisation of the ketone and a stabilisation of the enol, which agrees with the work of Lindner et al. [14] and with the large basis set of B3LYP [15].

This is supported by calculation of the Gibbs free energy $(\Delta G)$, which is found to be $1.639 \mathrm{kcal} / \mathrm{mol}$ and less than that of the parent (without fluorination, $7.792 \mathrm{kcal} / \mathrm{mol}$ ).

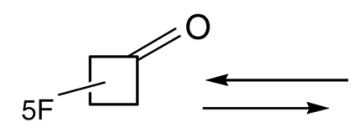

3<smiles>OC1=CC([SH-])C1</smiles>

4
This indicates that, perfluorination increases the stability of the enol tautomer relative to the keto tautomer. This $\Delta G$ value $(1.693 \mathrm{kcal} / \mathrm{mol})$ for perfluorination agrees with that calculated by $\mathrm{HF} / 6-311 \mathrm{G}^{* *} / / 6$ $311 \mathrm{G}^{* *}(2.3 \mathrm{kcal} / \mathrm{mol})$ and $\mathrm{MP} / 6-311 \mathrm{G}^{* *} / / 6-311 \mathrm{G}^{* *}$ $(1.1 \mathrm{kcal} / \mathrm{mol})$ [14].

This stabilization effect of the substituent (perfluorination) is often found by using isodesmic reactions (conserved bond type) [29]. A positive heat of reaction $\left(\Delta H_{\mathrm{r}}\right)$ indicates stabilization of the reactant by the substituent, and vice versa. The isodesmic reaction heat of $2 \mathrm{H}$-perfluorocyclobutanone $\mathbf{3}$ is $-13.897 \mathrm{kcal} / \mathrm{mol}$, indicating that perfluorination of cyclobutanone is an energetically unfavorable process.

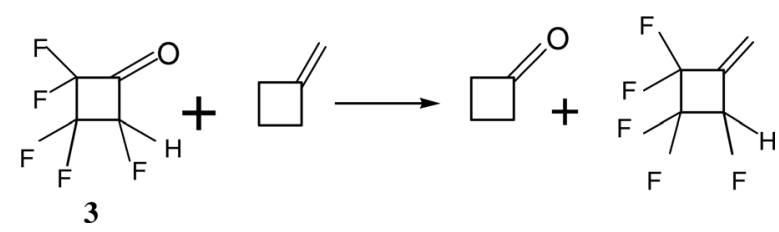

This almost agrees with ab initio calculation $(-17.4 \mathrm{kcal} / \mathrm{mol})$ [14]. For perfluorocyclobut-1-enol 4, the isodesmic reaction energy is $-6.259 \mathrm{kcal} / \mathrm{mol}$, indicating that perfluorination of cyclobut-1-enol $\mathbf{4}$ is an energetically more favorable process than that of cyclobutanone 3 (more positive), although both have negative values (unstable). 


\begin{tabular}{clllllllllll}
\hline Compd \# & C1 & C2 & C3 & C4 & C5 & H1 & H2 & O1 & O2 & N1 & F1 \\
\hline 1 & 3.444 & 4.085 & 3.930 & 4.085 & & 0.986 & 0.986 & 6.473 & & & \\
2 & 3.637 & 4.259 & 3.866 & 3.980 & & 0.748 & 0.958 & 6.436 & & & \\
3 & 3.588 & 3.820 & 3.322 & 3.389 & & 0.950 & & 6.329 & & & 7.258 \\
4 & 3.804 & 3.782 & 3.964 & 3.939 & & 0.724 & & 6.341 & & & 7.225 \\
5 & 3.404 & 4.273 & 3.905 & 4.086 & 2.666 & 0.943 & 0.990 & 6.434 & & & 7.452 \\
6 & 3.408 & 4.273 & 3.899 & 4.091 & & 0.936 & 1.006 & 6.434 & 6.568 & 3.885 & \\
7 & 3.446 & 4.061 & 3.934 & 4.085 & 3.903 & 0.987 & 1.016 & 6.464 & & 5.123 & \\
8 & 3.467 & 3.937 & 3.930 & 4.081 & & 1.061 & 0.929 & 6.466 & & 5.163 & \\
9 & 3.484 & 3.730 & 4.015 & 4.074 & & 1.077 & 0.999 & 6.455 & 6.448 & & \\
10 & 3.500 & 3.669 & 4.007 & 4.078 & & 1.041 & 0.974 & 6.433 & & & 7.339 \\
11 & 3.508 & 4.464 & 3.841 & 3.932 & 2.629 & 0.705 & 1.020 & 6.416 & & & 7.459 \\
12 & 3.489 & 4.466 & 3.837 & 4.015 & & 0.705 & 1.019 & 6.411 & 6.638 & 3.830 & \\
13 & 3.629 & 4.225 & 3.880 & 3.982 & 3.859 & 0.740 & 1.036 & 6.423 & & 4.225 & \\
14 & 3.763 & 4.072 & 3.959 & 3.947 & & 0.755 & 0.944 & 6.424 & & 5.113 & \\
15 & 3.809 & 3.853 & 3.971 & 3.932 & & 0.747 & 1.027 & 6.415 & 6.422 & & \\
16 & 3.804 & 3.782 & 3.964 & 3.939 & & 0.741 & 1.010 & & 6.407 & & 7.322 \\
\hline
\end{tabular}

Table 3. Calculated electron densities of substituted cyclobutanones and their enols (See Table 1 for numbering).

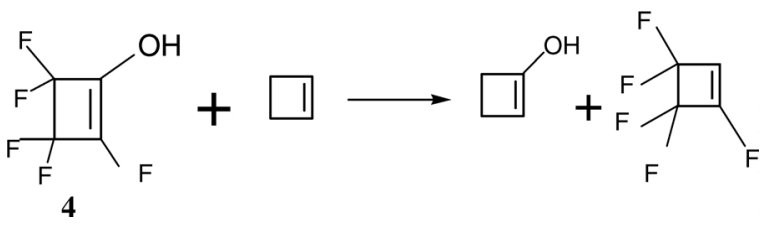

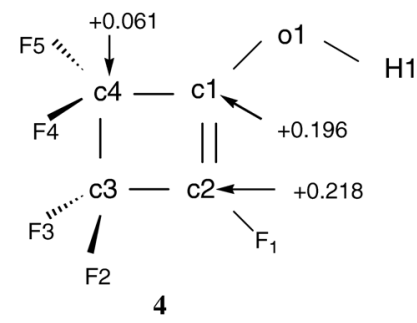

This almost agrees with ab initio calculation $(-5.5 \mathrm{kcal} / \mathrm{mol})$ [14]. These results suggest that the perfluorocyclobut-1-enol 4 stability is a consequence of ketone 3 destabilization.

The calculated charge distribution in $2 \mathrm{H}$-perfluorocyclobutanone $\mathbf{3}$, obtained from the electron density (Table 3), may give a plausible explanation for its destabilization. The calculated charge at the two $\alpha$ carbons $\mathrm{C} 2$ and $\mathrm{C} 4$ are more positive in the $2 \mathrm{H}$-perfluorocyclobutanone $3(+0.180,+0.611)$ than that in cyclobutanone 1 (parent) $(-0.085,-0.085)$.

The positive charge adjacent to carbonyl has a destabilizing effect due to the repulsion between the two positive alpha carbons in $\mathbf{3}$ might be responsible for its destabilization. The hydrogen $\mathrm{H} 1$ becomes more acidic $(+0.050)$ in $2 \mathrm{H}-3$ than in $\mathbf{1}(+0.015)$. Increasing the acidity of this hydrogen $\mathrm{H} 1$ is likely to be an important driving force for easy enolization, as was mentioned in previous work [14]. In the case of the enol $\mathbf{4}$, the electrostatic forces between two positive $\alpha$-carbons $\mathrm{C} 1, \mathrm{C} 4$ and the carbonyl carbon $\mathrm{C} 1$ are less repulsive than those in the ketone $\mathbf{3}$. Thus the enol tautomer $\mathbf{4}$ is favored over ketone tautomer $\mathbf{3}$, as was mentioned in $[15]$.

\subsection{Effect of Substituents on Cyclobutanone and Enol Counterpart}

Structural Details

Introduction of the substituents $\mathrm{CF}_{3}, \mathrm{NO}_{2}, \mathrm{CN}, \mathrm{NH}_{2}$ and $\mathrm{OH}$ at $\mathrm{C} 2$ of the cyclobutanone $\mathbf{1}$ (Table 1) cause an increase in the carbon-carbon bond lengths $\mathrm{C} 1-\mathrm{C} 2$ and $\mathrm{C} 2-\mathrm{C} 3$, and a decrease in the bond angle $\angle \mathrm{C} 1 \mathrm{C} 2 \mathrm{C} 3$, and it is most pronounced in the case of $\mathrm{CF}_{3}$ and $\mathrm{NO}_{2}$. The F substituent causes a slight decrease in the carbon-carbon bond lengths $\mathrm{C} 1-\mathrm{C} 2$ and $\mathrm{C} 2-\mathrm{C} 3$, and a slight increase in bond angle $\angle \mathrm{C} 1 \mathrm{C} 2 \mathrm{C} 3$.

In the case of cyclobut-1-enol, $\mathrm{CF}_{3}, \mathrm{NO}_{2}, \mathrm{CN}$, and $\mathrm{NH}_{2}$ as substituents cause an increase in carbon-carbon bond lengths of $\mathrm{C} 1=\mathrm{C} 2$ and $\mathrm{C} 2-\mathrm{C} 3$ and a decrease in the bond angle $<\mathrm{C} 1 \mathrm{C} 2 \mathrm{C} 3$, except the $\mathrm{OH}$ substituent which causes an increase in the bond angle (93.49 degrees). $\mathrm{F}$ as substituent causes a slight decrease in the carbon-carbon bond lengths $\mathrm{C} 1=\mathrm{C} 2$ and $\mathrm{C} 2-\mathrm{C} 3$, and an increase in bond the angle $<\mathrm{C} 1 \mathrm{C} 2 \mathrm{C} 3$. This is similar to the recent work on cyclopentanone and its enol counterpart [28].

\section{Stabilization by Substituents}

Thermodynamic calculations of Gibbs free energies $(\Delta G)$ for $\mathrm{CF}_{3}$ and $\mathrm{NO}_{2}$ substituents (Table 4) with negative values of $\Delta G(-6.857 \mathrm{kcal} / \mathrm{mol}$ for $\mathrm{CF}_{3}$ and $-11.457 \mathrm{kcal} / \mathrm{mol}$ for $\mathrm{NO}_{2}$ ) indicate that the reaction is spontaneous. That is to say the equilib- 
Table 4. Evaluation of substituent effect on cyclobutanones and their enols via isodesmic reactions.

\begin{tabular}{ccccccccc}
\hline & $\mathrm{CF}_{3}$ & $\mathrm{NO}_{2}$ & $\mathrm{CN}$ & $\mathrm{NH}_{2}$ & $\mathrm{OH}$ & $\mathrm{F}$ \\
\hline
\end{tabular}

Table 5. Evaluation of substituent effect on cyclobutanones and their enols via isodesmic reactions $(\Delta H \mathrm{r}$ in $\mathrm{kcal} / \mathrm{mol})$.

\begin{tabular}{ccccccccc} 
& & $\mathrm{CF}_{3}$ & $\mathrm{NO}_{2}$ & $\mathrm{CN}$ & $\mathrm{NH}_{2}$ & $\mathrm{OH}$ & $\mathrm{F}$ \\
\hline
\end{tabular}

rium shifts to the enol side. This is supported by the isodesmic reactions (Table 5), where $\Delta H \mathrm{r}$ for the enol isodesmic reactions in the case of $\mathrm{CF}_{3}$ and $\mathrm{NO}_{2}$ substituents $(7.305 \mathrm{kcal} / \mathrm{mol}$ and $5.383 \mathrm{kcal} / \mathrm{mol}$, respectively) are greater than that for the ketone isodesmic reactions in the case of $\mathrm{CF}_{3}$ and $\mathrm{NO}_{2}$ substituents $(0.319 \mathrm{kcal} / \mathrm{mol}, 0.008 \mathrm{kcal} / \mathrm{mol})$. This suggest that $\mathrm{CF}_{3}$ and $\mathrm{NO}_{2}$ destabilize the ketone. For $\mathrm{CN}$ substituent, $\Delta G=0.155 \mathrm{kcal} / \mathrm{mol}$ (Table 4), suggesting that the reaction is slightly not spontaneous. This is supported by the isodesmic reaction, where $\Delta H \mathrm{r}$ for the ketone $(\Delta H \mathrm{r}=1.341 \mathrm{kcal} / \mathrm{mol}$, Table 5) is slightly greater than that of the enol $(\Delta H \mathrm{r}=1.108 \mathrm{kcal} / \mathrm{mol}$, Table 5), suggesting slight stabilization of the ketone. Hence the equilibrium shifts to the ketone side. In the case of $\mathrm{NH}_{2}, \mathrm{OH}$ and $\mathrm{F}$ substituents, the $\Delta G$ values are all positive (Table 4 ) and more pronounced in the case of $\mathrm{F}$ as substituent $(\Delta G=9.841 \mathrm{kcal} / \mathrm{mol})$, suggesting that all the reactions are not spontaneous. i.e. $\mathrm{NH}_{2}, \mathrm{OH}$ and $\mathrm{F}$ stabilize the ketone. These results are supported by the isodesmic reactions (Table 5), where the $\Delta H \mathrm{r}$ values for the enol and ketone are negative, suggesting destabilization of the enols and ketones. But the $\Delta \mathrm{Hr}$ values for the ketones are more positive than those of the enoles, suggesting stabilization of the ketones. This agrees with present thermodynamic calculations and suggest that the $\mathrm{NH}_{2}, \mathrm{OH}$ and $\mathrm{F}$ substituents stabilize cyclobutanone.

\section{Electron Densities}

For cyclobutanone 1, it can be seen from Table 3 that $\mathrm{OH}, \mathrm{NH}_{2}$ and $\mathrm{F}$ decrease the electron density on $\mathrm{C} 2$ and increase the electron densities on $\mathrm{C} 1$ and $\mathrm{C} 3$. That is to say, they act as electron releasing. In the case of $\mathrm{CF}_{3}$ and $\mathrm{NO}_{2}$, the electron density increases on carbon $\mathrm{C} 2$ and decreases on the carbon atoms $\mathrm{C} 1$ and $\mathrm{C} 3$. This is most pronounced in the case of $\mathrm{NO}_{2}$. That is, these substituents act as electron withdrawing. $\mathrm{CN}$ acts as very weakly electron releasing [31].

In the case of cyclobut-1-enol $2, \mathrm{CF}_{3}$ and $\mathrm{NO}_{2}$ act as electron withdrawing. The $\mathrm{CN}$ substituent decreases slightly the electron density on $\mathrm{C} 1$, and increases it slightly on $\mathrm{C} 3$, which indicates that the $\mathrm{CN}$ group behaves as electron withdrawing when attached to a system with high electron density (in this case $\mathrm{C}=\mathrm{C}$ bond) and as electron releasing when attached to a system with low electron density (such as C-C bond). In other words, the $\mathrm{CN}$ group behaves according to the electron demand, i.e. it shows amphielectronic behavior $[28,31-38]$. The $\mathrm{NH}_{2}$ and $\mathrm{OH}$ substituents act as electron releasing.

\section{Conclusion}

It can be concluded that cyclobutanone $\mathbf{1}$ is more stable than its enol counterpart 2 . The perfluorination destabilizes the ketone (shift to the enol side), in better agreement with the experimental results than the theoretical calculations. The shift in equilibrium to the enol side is attributed to the ketone destabilization and not to the enol stabilization. All the substituents have some effect on the geometrical parameters. Strong electron releasing substituents (e.g. $\mathrm{NH}_{2}, \mathrm{OH}, \mathrm{F}$ ) stabilize the cyclobutanone $\mathbf{1}$ while strong electron withdrawing 
substituents (e.g. $\mathrm{CF}_{3}, \mathrm{NO}_{2}$ ) destabilize the cyclobutanone $\mathbf{1 .}$

[1] Z. Rapport, Ed., The Chemistry of Enols; Wiley, Chichester 1990, U.K.

[2] K. Lammertsma and B. V. Prasad, J. Amer. Chem. Soc. 116, 642 (1994).

[3] K. Lammertsma and B. V. Prasad, J. Amer. Chem. Soc. 115, 2348 (1993).

[4] J. Albert, A. Gonzalez, J. Granell, R. Moragas, C. Puerta, and P. Valerga, Organometallics 16, 3775 (1997).

[5] a) ?. Ershov and ?. Nikiforov, Russ. Chem. Rev. 35, 817 (1996); b) D. D. J. Neto and R. B. Dealencastro, Int. J. Quantum Chem. 20, 107 (1993).

[6] Chien-Chih Su, Chao-Kuo Lin, Chen-Chang Wu, and Min-Hesiung Lien, J. Phys. Chem. A 103, 3289 (1999).

[7] B. Capon, B. Z. Guo, F. C. Kwok, A. K. Siddhanta, and C. Zucco, Acc. Chem. Res. 21, 135 (1988).

[8] D. P. Chong and C. H. Hu, J. Electron. Spectrosc. 94, 181 (1998).

[9] F. Bauder, H. Tank, and D. Gunthard, Chem. Acta 46, 1453 (1963).

[10] J. R. During and R. C. Lord, J. Chem. Phys. 45, 61 (1966).

[11] K. Tamagawa and R. L. Hilderbrandt, J. Phys. Chem. 87, 5508 (1983)

[12] E. Hopkinson and Lee-Ruff, Tetrahedron 44, 6815 (1988).

[13] R. A. Bekker, V. Ya. Popkova, and I. L. Knunyomts, Dokl. Akad. Nauk, SSSR 103, 235 (1977).

[14] P.E. Lindner, R. A. Correa, J. Gino, and D. M. Lemal, J. Amer. Chem. Soc. 118, 2556 (1996).

[15] Y. Kwon, J. Mol. Struct. (Theochem) 488, 93 (1999).

[16] (a) S. M. Khalil and M. Shanshal, Theor. Chim. Acta. 46, 23 (1977); (b) S. M. Khalil and M. Shanshal, Z. Naturforsch. 33a, 722 (1978); (c) S. M. Khalil, Z. Naturforsch. 40a, 1278 (1985); (d) A. G. Abed and S.M. Khalil, Z. Naturforsch. 54a, 251 (1999).

[17] R. C. Bingham, M. J. S. Dewar, and D. H. Lo, J. Amer. Chem. Soc. 97, 1285 (1975).

[18] B. A. Murtagh and R.W.H. Sargent, Comput. J. 13, 185 (1970).

[19] P. Pulay, Mol. Phys. 17, 197 (1969).
[20] D. A. Dixon and B. E. Smart, J. Phys. Chem. 95, 1609 (1991).

[21] F. Turecek and C. J. Cramer, J. Amer. Chem. Soc. 117, 12243 (1995).

[22] R. M. Less and J. G. Baker, J. Chem. Phys. 48, 5299 (1968).

[23] J. P. Culot, "Austin Symposium on Gas Phase Molecular Structure 4", paper T8 (1972).

[24] M. Rodler and A. Bauder, J. Amer. Chem. Soc. 106, 4025 (1984).

[25] K. Kuchitsu, J. Chem. Phys. 49, 4456 (1968).

[26] J. M. Stone and I. M. Mills, Mol. Phys. 18, 631 (1970).

[27] A. El-Alali, A. A. Marashdeh, and S. M. Khalil, Z. Naturforsch. 58a, 749 (2003).

[28] M. S. Al-Noeemat, R. A. Al-Ma'ani, and S. M. Khalil, ibid, 58a, 738 (2003).

[29] (a) S. M. Khalil and H. M. Jarjis, Z. Naturforsch. 46a, 898 (1991); (b) W. H. Hehre, R. Ditchfield, L. Radom, and J. A. Pople, J. Amer. Chem. Soc. 72, 4796 (1970); (c) M. H. Lien and A.C. Hopkinson, J. Phys. Chem. 88, 1513 (1984); (d) S. M. Khalil, and H. M. Jarjis, Z. Naturforsch. 42a, 761 (1987).

[30] N. Heinrich, W. Koch, G. Frenking, and H. Schwarz, J. Amer. Chem. Soc. 108, 593 (1986).

[31] N. M. Yahya and S. M. Khalil, Z. Naturforsch. 47a, 768 (1992).

[32] L. Radom, P. C. Hariharan, J. A. Pople, and P. V. R. Schleyer, J. Amer. Chem. Soc. 98, 10 (1976).

[33] H. M. Jarjis and S. M. Khalil, J. Chem. Soc. Perkin Trans. II, 1701 (1986).

[34] W. F. Reynolds, P. Dais, R. W. Taft, and R. D. Topsom, Tetrahedron Lett. 22, 1795 (1981).

[35] S. M. Khalil and H. M. Jarjis, Z. Naturforsch. 46a, 247 (1990).

[36] R. G. Gassman and J. J. Talley, J. Amer. Chem. Soc. 102, 1214 (1980).

[37] D. A. Dixon, P. A. Charlier, and R. G. Gassman, J. Amer. Chem. Soc. 102, 3957 (1980).

[38] M. N. Paddon-Row, C. Santiago, and K. W. Houk, J. Amer. Chem. Soc. 102, 6561 (1980). 